\title{
Electron Microscopy Views of Dimorphic Chloroplasts in C4 Plants
}

\author{
Keith Ka Ki Mai, Peng Gao and Byung-Ho Kang* \\ Centre for Cell and Developmental Biology, State Key Laboratory for Agrobiotechnology, School of Life Sciences, The Chinese \\ University of Hong Kong, Hong Kong, Hong Kong
}

C4 plants enhance photosynthesis efficiency by concentrating $\mathrm{CO}_{2}$ to the site of Rubisco action. Chloroplasts in C4 plants exhibit structural dimorphism because thylakoid architectures vary depending on energy requirements. Advances in electron microscopy imaging capacity and sample preparation technologies allowed characterization of thylakoid structures and their macromolecular arrangements with unprecedented precision mostly in C3 plants. The thylakoid is assembled during chloroplast biogenesis through collaboration between the plastid and nuclear genomes. Recently, the membrane dynamics involved in the assembly process has been investigated with 3D electron microscopy, and molecular factors

OPEN ACCESS

Edited by:

Elison B. Blancaflor,

Noble Research Institute, LLC

United States

Reviewed by:

Roma Mukhopadhyay,

Washington State University,

United States

Agnieszka Mostowska,

University of Warsaw, Poland

*Correspondence:

Byung-Ho Kang

bkang@cuhk.edu.hk

Specialty section:

This article was submitted to

Plant Cell Biology,

a section of the journal

Frontiers in Plant Science

Received: 19 April 2020

Accepted: 22 June 2020

Published: 03 July 2020

Citation:

Mai KKK, Gao P and Kang B-H (2020)

Electron Microscopy Views of

Dimorphic Chloroplasts in C4 Plants.

Front. Plant Sci. 11:1020.

doi: 10.3389/fp/s.2020.01020 required for thylakoid construction have been characterized. The two classes of chloroplasts in C4 plants arise from common precursors, but little is known about how a single type of chloroplasts grow, divide, and differentiate to mature into distinct chloroplasts. Here, we outline the thylakoid structure and its assembly processes in C3 plants to discuss ultrastructural analyses of dimorphic chloroplast biogenesis in C4 plant species. Future directions for electron microscopy research of 44 photosynthetic systems are also proposed.

Keywords: chloroplast, thylakoid, C4 photosynthesis, single-cell C4 plants, electron microscopy, electron tomography

\section{INTRODUCTION}

Since the early days of microscopy, chloroplasts have attracted attention from microscopists. They are abundant in leaves, larger than other organelles, and do not require staining for microscopic imaging. As reviewed by Staehelin in 2003, the study of chloroplast structure has advanced with enhancements in light and electron microscopy from two-dimensional transmission electron microscopy (TEM) imaging to three-dimensional (3D) electron tomography (ET) and with improvements in sample preservation from chemically preservation to freeze-fracture to highpressure freezing (Staehelin, 2003). The innovations in electron microscopy technology have enabled plant cell biologists to monitor structural and functional dynamics of chloroplasts at nanometer resolution in molecular detail (Kirchhoff, 2018).

The earliest 3D model for the complex thylakoid structure in the chloroplast observed in electron micrographs was the helical model proposed by Paolillo and later modified by Brangeon and Mustárdy (Brangeon and Mustardy, 1979; Mustárdy et al., 2008; Lindquist et al., 2016). In this model, the granum stack is joined to the stroma thylakoid by a series of right-handed helices. This model helps explain why the same stroma thylakoid appears to attach to different grana thylakoids in different parts of the grana stack and why it appears shifted in opposite directions at opposite 
sides of the granum. Shimoni et al. (2005) proposed a different model based on ET data known as the bifurcation model. In this model, the grana stacks consist of repeating units of bifurcations of the stroma lamellae. Later studies employing cryo-electron tomography (cryo-ET), provided evidence in support of the helical model (Austin and Staehelin, 2011; Daum and Kuhlbrandt, 2011). The helical model is now the most widely accepted model for thylakoid architecture in higher plants. It was recently demonstrated that the thylakoid's helical arrangement is for constituting an interconnected network of densely packed membrane layers using ET analysis and energy minimization modeling of thylakoid membranes (Bussi et al., 2019), as was observed in the helical arrangement of the rough endoplasmic reticulum in secretory cells (Terasaki et al., 2013).

The high-resolution 3D morphological analyses of chloroplasts have been focused on those in Arabidopsis thaliana (Arabidopsis) and legume species. These plants are classified as C3, and their chloroplasts are thought to be uniform with respect to photosynthesis. By contrast, C4 plants have two types of chloroplasts that suppress photorespiration by the ribulose-1,5-bisphosphate carboxylase/oxygenase (Rubisco) (Edwards et al., 2001). One type of chloroplast fixes $\mathrm{CO}_{2}$ to generate four carbon (C4) acids. In the other type of chloroplast, the Calvin cycle occurs, which regenerates $\mathrm{CO}_{2}$ from the $\mathrm{C} 4$ acids. Cycles of $\mathrm{C} 4$ acids pump $\mathrm{CO}_{2}$ near Rubisco. These functionally distinct chloroplasts are readily distinguished in electron micrographs (Voznesenskaya et al., 1999).

Because $\mathrm{C} 4$ plants grow better than $\mathrm{C} 3$ plants under adverse conditions, molecular mechanisms of $\mathrm{C} 4$ photosynthesis have been investigated with a goal to introduce merits of $\mathrm{C} 4$ plants into $\mathrm{C} 3$ plants (Leegood, 2002; Gowik and Westhoff, 2011). C4 grasses include maize, sorghum, and sugarcane, which are valuable, widely cultivated crop plants. Another interesting aspect of $\mathrm{C} 4$ photosynthesis is its anatomical variations. $\mathrm{C} 4$ cycles were originally thought to operate between two adjacent cells but this notion was challenged when singlecell C4 (SCC4) plants, in which $\mathrm{CO}_{2}$ transport occurs within single photosynthetic cells, were discovered (Voznesenskaya et al., 2001; Edwards et al., 2004).

In this review, we summarize the macromolecular organizations of thylakoids in C3 plants and discuss their assembly process during chloroplast biogenesis with an emphasis on what has been learned from electron microscopy/tomography analyses. We will review the link between structures and functions of dimorphic chloroplasts in mature leaves of maize (a C4 plant with Kranz anatomy) and Bienertia sinuspersici (a SCC4 plant). These systems were chosen for discussion because diversification of maize and $B$. sinuspersici chloroplasts for the $\mathrm{C} 4$ leaf development have has been characterized at the level of electron microscopy/tomography. Further ultrastructural studies to fill gaps in our understanding of the $\mathrm{C} 4$ photosynthetic machinery are proposed.

\section{MACROMOLECULAR CONSTITUENTS OF THE THYLAKOID MEMBRANE}

Large protein complexes of the electron transport chain embedded in the thylakoid membrane are differentially distributed in the helical architecture. PSII and its LHCB subunits are confined to the stacked grana region of the helix. They are closely packed in the region, forming semicrystalline arrays. By contrast, ATP synthase and PSI complexes are known to be excluded from the interiors of grana thylakoid because of their large stroma-facing subunits (Dekker and Boekema, 2005). The localization of cytochrome $b_{6} f$ complex has proven to be controversial but is generally recognized to be between the stacked and unstacked regions (Nevo et al., 2012). It has also been postulated that access of cytochrome $b_{6} f$ to the grana core is regulated by the stromal gap (Kirchhoff et al., 2017).

PSII-LHCBII complexes and CURVATURE THYLAKOID1 (CURT1) appear to be important for stack formation in thylakoids (Armbruster et al., 2013). Cryo-ET revealed the arrangement of PSII and its associated proteins in thylakoid membranes of spinach and pea (Daum et al., 2010). The interactions between PSII and its LHCB subunits appear to mediate the stacking of thylakoid membranes. The small CURT1 proteins are embedded in the sharply curved membrane at the edge of grana stacks in Arabidopsis. The abundance of CURT1 proteins leads to narrow grana stacks with more layers, whereas the absence of CURT1 results in large increases of grana diameters and suppresses grana stacking (Pribil et al., 2018).

The protein complexes of the chloroplast electron transport chain require lipid membranes for chemiosmosis. Four lipids, monogalactosyldiacylglycerol (MGDG), digalactosyldiacylglycerol (DGDG), sulfoquinovosyldiacylglycerol (SQDG), and phosphatidylglycerol (PG), are the major lipid species of the thylakoid membrane. The cone-shaped MGDG is a non-bilayer forming lipid; DGDG, SQDG, and PG are bilayer forming lipids (Rocha et al., 2018). An in vitro study of thylakoid bilayers of pea chloroplasts showed that MGDG promotes membrane appression within the grana stacks and possibly stabilizes the inner membrane leaflet of the curve margins within each grana disc (Seiwert et al., 2018). DGDG is proposed to be involved in membrane stacking via hydrogen bonds between adjacent bilayers (Demé et al., 2014). It was shown that thylakoid lipid synthesis and photosynthetic gene regulation are coordinated by analysis of a mutant with severe loss of galactolipids (Kobayashi et al., 2013).

\section{ULTRASTRUCTURAL ANALYSES OF CHLOROPLAST BIOGENESIS}

The hallmark of chloroplast biogenesis is construction of thylakoids in the stroma (Pogson et al., 2015). The proplastid is a small undifferentiated plastid with no internal structures except for residual membranes. Proplastids in the seed transform directly into chloroplasts if the seed germinates and grows under light, and the thylakoid assembly process during this transformation has been examined with ET (Liang et al., 2018). Soon after germination, the tubulovesicular residual membranes in the proplastids expand and then become flattened. This transformation requires binding of polysomes on their surface, suggesting that the process involves insertion of thylakoid membrane proteins. Subsequently, these monolayered membrane sheets merge into a single 3D network spanning the length of the plastid, and small stacks consisting of two 
or three layers derived from polysome-coated buds appear at many sites in the network. These pro-granal stacks gradually mature into full-fledged grana stacks. RNA-seq and immunoblot analysis revealed that PSII is the first of the major protein complexes to be established in the thylakoid membrane in proplastids of germinating Arabidopsis cotyledons (Liang et al., 2018).

Proplastids in the seed first develop into etioplasts if germinated under darkness. Etioplasts contain materials necessary for constructing thylakoids so that they can rapidly reshape into chloroplasts when light becomes available (Rudowska et al., 2012). Light-induced chloroplast biogenesis was examined in chemically fixed bean leaf samples with ET by Kowalewska et al. (2016) They showed that the paracrystalline prolamellar bodies lose lattice-like regularity upon illumination to become planar precursors of thylakoids and that grana stacks arise from the flattened membranes. Spectral and electrophoretic analyses indicated that PSII accumulation coincides with appearance of grana stacks in developing chloroplasts and that subunits of PSI and PSII are detected simultaneously (Kowalewska et al., 2016). 3D architectures of prolamellar bodies and intermediates of their transformation into thylakoids have not been determined in cryopreserved samples yet.

Chloroplasts in true leaves arise from proplastids in the shoot apical meristem (SAM). Proplastids in SAM have more elaborate membrane elements than proplastids in the seed. Some of the membrane elements exhibit basic stack architectures that grow and fuse to construct the mature thylakoid network as the SAM gives rise to mature leaves (Charuvi et al., 2012). Interestingly, proplastids in the precursors of epidermal cells lose thylakoids, undergoing changes opposite from proplastids in other cells in the SAM. It has not been examined whether epidermal cells in germinating cotyledon exhibit cell type-specific plastid transformations.

One of the characteristics of the proplastid-to-chloroplast conversion is that discrete thylakoid present in proplastids become interconnected to constitute the organelle-wide membrane network in the mature chloroplast. Individual thylakoids remain unconnected in chloroplasts of $f z l$ mutant plants (Liang et al., 2018), indicating that FZL, which is an Arabidopsis dynamin targeted to the stroma (Gao et al., 2006), is involved in thylakoid membrane fusion. The animal and fungal Fzo dynamins mediate fusion of mitochondrial outer membranes in the cytosol (Breckenridge et al., 2009; Wang et al., 2016). Despite differences in substrates and sites of action, fusionpromoting functions of the dynamin family proteins appear to be conserved across the kingdoms.

\section{DIMORPHIC CHLOROPLASTS IN SINGLE-CELL C4 PLANTS AND MAIZE}

C4 plants have two types of chloroplasts: one for fixing $\mathrm{CO}_{2}$ and the other that allows Rubisco to function at increased $\mathrm{CO}_{2}$ partial pressure (Edwards et al., 2001). The functional differences are linked to differential energy requirements and the distinction is illustrated in their thylakoid architectures visualized by TEM. One group of chloroplasts run linear electron flow consisting of both PSII and PSI to produce ATP and reducing power. Because PSII-LHCII complexes in the opposite thylakoid membranes can bind to each other, these chloroplasts have grana stacks and interconnecting stroma lamellae. The second type produce primarily ATP via cyclic electron flow through PSI and grana stacks are rare in these chloroplasts (Langdale et al., 1988; Evert et al., 1996). The maize is a C4 plant with Kranz anatomy in which functionally distinct chloroplasts are separately located in the mesophyll cell (MC) and in the bundle sheath cell (BSC) and they exhibit dimorphism related to the differential energy requirements (Sedelnikova et al., 2018).

In SCC4 plants, the two classes of chloroplasts are spatially segregated within a single cell (Freitag and Stichler, 2002; Akhani et al., 2005; Akhani et al., 2012). At least four species, Suaeda aralocaspica, Bienertia cycloptera, Bienertia sinuspersici, and Bienertia kavirense, have been found to exhibit single-cell C4 photosynthesis (Sharpe and Offermann, 2013). Intra-cellular organization of the dimorphic chloroplasts differs dramatically between the Suaeda-type and the Bienertia-type plants. In Suaedatype SCC4 plants, the dimorphic chloroplasts are organized into distal and proximal chloroplasts at the poles of the cell, whereas in Bienertia-type SCC4 plants there are central and peripheral chloroplasts (Koteyeva et al., 2016).

B. sinuspersici has an NAD-ME type $\mathrm{C} 4$ cycle with peripheral and central chloroplasts that are functionally analogous to chloroplasts in BSC and MC, respectively, in Kranz-type C4 species (Offermann et al., 2011; Koteyeva et al., 2016; Ludwig, 2016; Rao and Dixon, 2016). The central chloroplasts in are arranged in an ovoid shape, and their thylakoids consist of grana stacks and unstacked stroma thylakoids (Figure 1). Their peripheral chloroplasts are disk-shaped and oppressed within the thin cytoplasmic gap between the vacuolar membrane and the plasma membrane. Stacked thylakoids are rarer in the peripheral chloroplast (Figure 1). Linear electron flow necessary for production of NADPH and ATP occurs in the thylakoids of central chloroplasts, whereas peripheral chloroplasts use ATP to convert $\mathrm{CO}_{2}$ into aspartates. By contrast, the $\mathrm{C} 4$ biochemistry in maize is primarily of the NADP-malic enzyme (NADP-ME) type in which chloroplasts in MCs need both PSII and PSI for linear electron flow (Arrivault et al., 2017).

\section{BIOGENESIS OF DIMORPHIC CHLOROPLASTS IN A SINGLE-CELL C4 PLANT, BIENERTIA SINUSPERSICI}

Among SCC4 plant species, photosynthesis of B. sinuspersici has been studied most thoroughly (Minges et al., 2019). The development of $B$. sinuspersici photosynthetic apparatus happens along a gradient with the younger chlorenchyma cells at the leaf base and the more mature cells at the tip (Lara et al., 2008). In the young cells, C3 photosynthesis occurs, and all chloroplasts have similar levels of Rubisco mRNA. Selective enrichment of Rubisco in the central chloroplast cluster is a key $\mathrm{C} 4$ characteristic, and this feature emerges in a longitudinal progression of the chlorenchyma cell maturation (Koteyeva et al., 2016). Park et al. have classified the B. sinuspersici SCC4 cell 


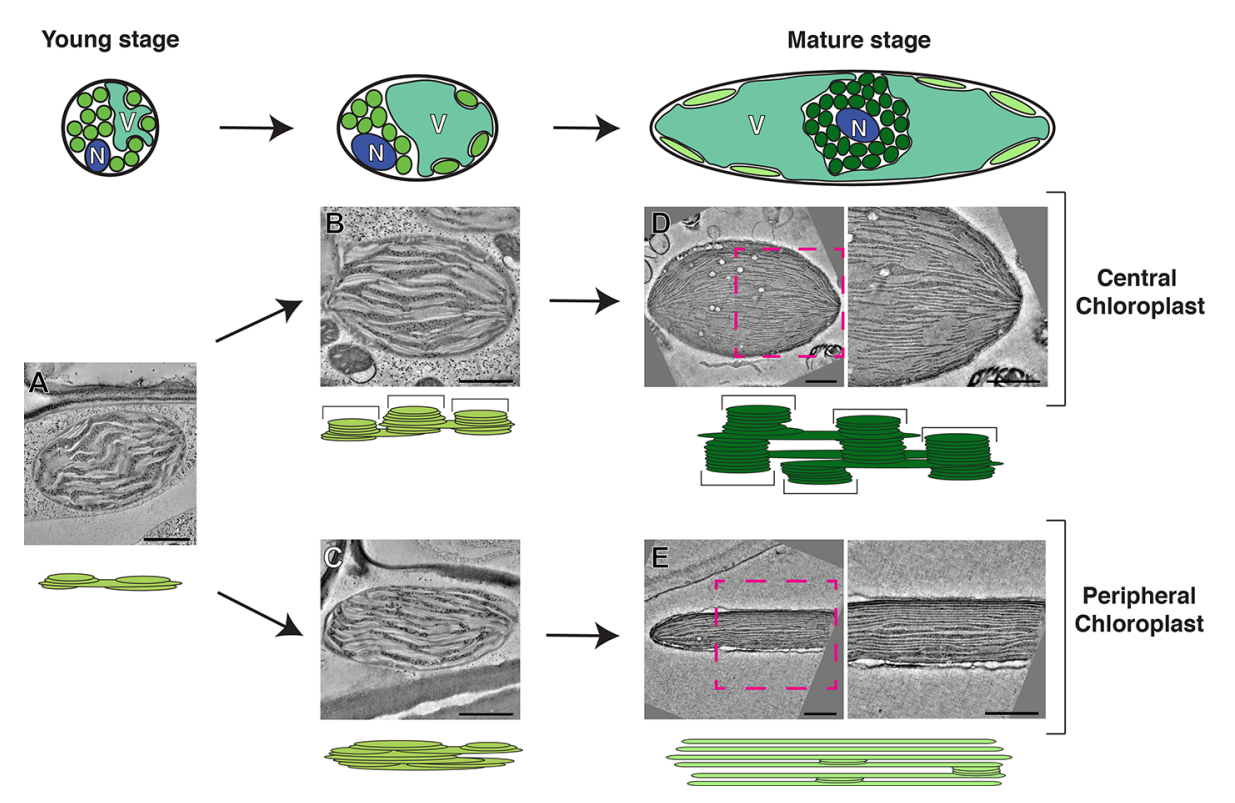

FIGURE 1 | Model of the development of photosynthetic cells and their dimorphic chloroplasts in SCC4 plant Bienertia sinuspersici. Cells at the young stage (left) are small and round. Their cytoplasm has not been divided into central and peripheral regions because their vacuoles have not developed. Chloroplast in the young stage cells have simple thylakoid network with primitive grana stacks (A). Chloroplasts are being segregated in the intermediate stage cells as the vacuole enlarges (middle). Grana stacks (brackets in the diagram) are discerned from unstacked lamellae in the central chloroplasts (B) while thylakoids in the peripheral chloroplast are more intertwined, making it difficult to distinguish grana stacks from stroma thylakoid (C). In the mature stage (right), the cells have enlarged and most of the volume of the cell consists of a single vacuole. The central chloroplast (dark green) has taken on an ovoid shape with clearly delineated tall grana stacks (D). The peripheral chloroplast (light green) has been flattened into discus shape. The majority of the thylakoid network consists of single-layer stroma lamellae with a smaller number of simple grana stacks (E). For each stage, thylakoid models and electron tomographic slice images of corresponding chloroplasts are shown. N, nucleus; V, vacuole. Bars indicate $500 \mathrm{~nm}$. The model is based on data published in Akhani et al. (2005); Koteyeva et al. (2016), and Mai et al. (2019).

maturation into four stages (Park et al., 2008). In the youngest stage, no distinction between central and peripheral chloroplasts is observed. In later stages, the chloroplasts are separated by growing vacuoles until there is a clear central chloroplast compartment containing tightly packed central chloroplasts, almost all mitochondria, and the nucleus. Transcripts encoding Rubisco are concentrated in the central domain in the mature chlorenchyma cells (Voznesenskaya et al., 2005; Koteyeva et al., 2016). The positioning of the peripheral chloroplasts is dependent upon the cytoskeleton, which maintains the spatial integrity of the SCC4 structure (Chuong et al., 2006).

The biogenesis of dimorphic chloroplasts in SCC4 plants requires differential targeting of nucleus-encoded chloroplast proteins to the two types of chloroplasts. Theories for explaining how proteins from nuclear encoded genes are selectively targeted include selective protein degradation, mRNA targeting, and selective import (Offermann et al., 2015; Erlinghaeuser et al., 2016). Wimmer et al. provided evidence that transit peptides of $B$. sinuspersici chloroplast proteins have two elements, one for general chloroplast import and the other for selective targeting (Wimmer et al., 2017). Plastidtargeted pyruvate orthophosphate-dikinases (PPDKs) in C4 plants regenerate phosphoenolpyruvate, the $\mathrm{CO} 2$ acceptor in $\mathrm{C} 4$ cycle. By contrast to PPDKs in C4 plants, functions of plastid-targeted PPDKs in C3 plants have not been characterized well (Chastain et al., 2011). B. sinuspersici chlorenchyma cells have PPDKs in their peripheral chloroplasts; the specific localization requires a sequence element in
PPDK that blocks its entry into central chloroplasts. A recent electron tomography (ET) imaging of B. sinuspersici visualized the process of chloroplast differentiation (Mai et al., 2019). Young chloroplasts have grana stacks and stroma lamellae and they are not morphologically distinguishable before spatially separated by the central vacuole. Grana stacks of chloroplasts located in the cell center multiply and each acquires more layers. By contrast, grana stacks displaced to the cell periphery stretch out, gradually losing the stack architecture to the degree that most thylakoids become monolayered. The process of dimorphic chloroplast biogenesis in B. sinuspersici is summarized in Figure 1. It was suggested that invaginations from the inner envelope membrane supply materials for thylakoid expansion because the membrane ingrowths stretch out to become associated with existing thylakoids.

In addition, TEM/ET study of $B$. sinuspersici chloroplasts revealed how thylakoids are partitioned in dividing chloroplasts. It is difficult to capture dividing chloroplasts by TEM because chloroplasts divide less frequently than proplastids in the meristematic cells. Dozens of chloroplasts are clustered in B. sinuspersici cells and they proliferate by binary fission. In ET slice images of chloroplast undergoing fission, thylakoids at the division plane were severed before the envelopes were squeezed (Mai et al., 2019). Interestingly, PSII complexes are dislocated from the division site probably because they constitute closely packed $2 \mathrm{D}$ array that could block thylakoid severing. It has been shown that two ring complexes, one ring on outer envelope membrane and the other ring inside the inner envelope membrane 


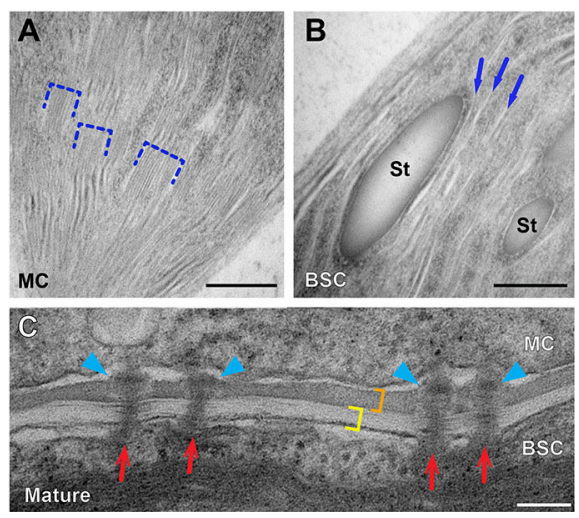

D Mature maize leaf cells
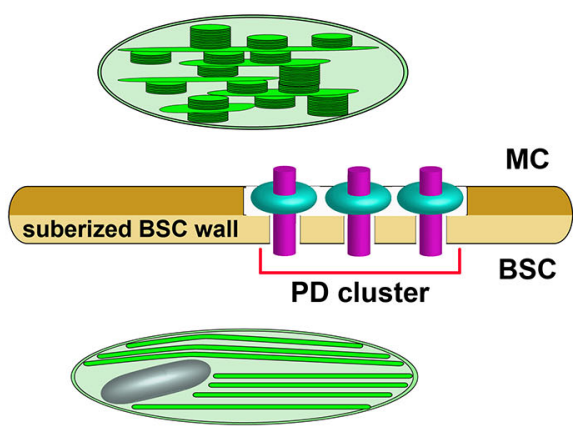

FIGURE 2 | Dimorphic chloroplasts and plasmodesmata in Kranz anatomy of the maize leaf. (A, B) Transmission electron micrographs of a mesophyll cell (MC) chloroplast and a bundle sheath cell (BSC) chloroplast. Grana stacks (dashed brackets) are abundant in the MC chloroplast (A). Thylakoids are monolayered in the BSC chloroplast (B). Three unstacked stroma lamellae are marked with arrows in B. (C) Plasmodesmata (PD) at the MC-BSC interface of mature (D) maize leaf tissues. PD (red arrows) in the mature tissue have "sphincter" rings in the MC side wall (blue arrowheads). The BSC wall (yellow bracket) is suberized and it is stained differentially from the MC wall (orange bracket). (D) A diagram illustrating the dimorphic chloroplasts and PD in the maize leaf based on data published in 1996; Evert et al. (1977); Danila et al. (2016), and Mertz and Brutnell (2014). MCs and BSCs are linked via clusters of specialized PD that transverse a suberized cell wall. St: starch particle. Scale bars in (A, B) and (C, D) indicate $500 \mathrm{~nm}$, and $100 \mathrm{~nm}$, respectively.

assemble at the midzone of a dividing plastids to constrict the envelope membranes (Osteryoung and Pyke, 2014). GTPases, including DRP5B and FtsZ, and regulatory proteins were shown to constitute the ring complexes. However, no information about the molecular machinery constricting thylakoids is available (Chen et al., 2018).

\section{CONCLUSIONS AND FUTURE PROSPECTS}

Use of ET and cryo-preservation techniques has led to a better understanding of chloroplast structures and their biogenesis. Correlative gene expression analyses, biochemical analyses, and photosynthetic activity measurements provided further insight into the molecular mechanisms of thylakoid assembly. Novel membrane elements in the chloroplast will be uncovered in cryo-fixed plant cell samples (Kirchhoff, 2018). Intermediates of membrane assembly that were not previously documented are discerned in highpressure frozen plant cell samples because these structures are not lost during chemical fixation that takes minutes to hours (Staehelin and Kang, 2008; Wang et al., 2017; Karahara and Kang, 2013; Wang et al., 2019). For example, the kinked thylakoid membranes at the midplane of dividing chloroplasts have not been reported until Mai et al. (2019) where photosynthetic cells of Arabidopsis and B. sinuspersici were preserved by high pressure freezing. Combined with ET, transient structures in the thylakoid during its partitioning was revealed at nanometer-level resolutions.

Given the significance of maize as a crop plant, it is reasonable that the development of C4 cycle in BSC and MC has been characterized along the developmental gradient of the maize leaf blade by means of proteomic and transcriptomic approaches (Li et al., 2010; Majeran et al., 2010; Tausta et al., 2014; Wang et al., 2014). Majeran et al. (2010) carried out comparison of chloroplast structures in BSCs and MCs with conventional TEM after chemical fixation for correlating the morphological diversification with cell type-specific accumulation of thylakoid membrane proteins. ET and high-pressure freezing have not been adopted for investigating structural dynamics involved in the biogenesis of maize dimorphic chloroplasts at multiple developmental stages of Kranz anatomy. It remains elusive how grana stacksassembleand proliferatein MCchloroplasts whiletheydegenerate in BSC chloroplasts. Dual cell C4 cycle employs symplastictransportand it has been demonstrated that plasmodesmata (PD) connecting MC and BSC in the mature maize leaf cluster to form pitfields (Danila et al., 2016) and they are equipped with a unique "sphincter" module (Evert et al., 1977; Bilska and Sowinski, 2010). It is not understood whether the attachment of $\mathrm{PD}$ is involved in the maize $\mathrm{C} 4$ cycle and regulation of $\mathrm{C} 4$ photosynthesis (Figure 2). We expect that advanced electron microscopy methods will continue to reveal novel aspects of the structural biology of the $\mathrm{C} 4$ photosynthetic machinery.

\section{AUTHOR CONTRIBUTIONS}

KM and PG prepared figures. KM, PG, and B-HK wrote the manuscript. All authors contributed to the article and approved the submitted version.

\section{FUNDING}

We are grateful for support from Rural Development Administration of Korea (Project No. 10953092019), Hong Kong Research Grant Council (GRF14121019, GRF14126116, AoE/M-05/12, C4002-17G), and Chinese University of Hong Kong (Direct Grants).

\section{ACKNOWLEDGMENTS}

We apologize to researchers whose work has not been included in this manuscript owing to space limit. 


\section{REFERENCES}

Akhani, H., Barroca, J., Koteeva, N., Voznesenskaya, E., Franceschi, V., Edwards, G., et al. (2005). Bienertia sinuspersici (Chenopodiaceae): a new species from southwest Asia and discovery of a third terrestrial C4 plant without Kranz anatomy. Syst. Bot. 30, 290-301. doi: 10.1600/0363644054223684

Akhani, H., Chatrenoor, T., Dehghani, M., Khoshravesh, R., Mahdavi, P., and Matinzadeh, Z. (2012). A new species of Bienertia(Chenopodiaceae) from Iranian salt deserts: A third species of the genus and discovery of a fourth terrestrial C 4plant without Kranz anatomy. Plant Biosyst. - Int. J. Dealing Asp. Plant Biol. 4, 1-10. doi: 10.1080/11263504.2012.662921

Armbruster, U., Labs, M., Pribil, M., Viola, S., Xu, W., Scharfenberg, M., et al. (2013). Arabidopsis CURVATURE THYLAKOID1 proteins modify thylakoid architecture by inducing membrane curvature. Plant Cell Online 25, 26612678. doi: $10.1105 /$ tpc. 113.113118

Arrivault, S., Obata, T., Szecówka, M., Mengin, V., Guenther, M., Hoehne, M., et al. (2017). Metabolite pools and carbon flow during C 4photosynthesis in maize: 13CO 2labeling kinetics and cell type fractionation. J. Exp. Bot. 68, 283298. doi: 10.1093/jxb/erw414

Austin, J. R., and Staehelin, L. A. (2011). Three-dimensional architecture of grana and stroma thylakoids of higher plants as determined by electron tomography. Plant Physiol. 155, 1601-1611. doi: 10.1104/pp.110.170647

Bilska, A., and Sowinski, P. (2010). Closure of plasmodesmata in maize (Zea mays) at low temperature: a new mechanism for inhibition of photosynthesis. Ann. Bot. 106, 675-686. doi: 10.1093/aob/mcq169

Brangeon, J., and Mustardy, L. (1979). ontogenetic assembly of intra-chloroplastic lamellae viewed in 3-dimension. Biol. Cellulaire 36, 71-80.

Breckenridge, D. G., Kang, B.-H., and Xue, D. (2009). Bcl-2 proteins EGL-1 and CED-9 do not regulate mitochondrial fission or fusion in Caenorhabditis elegans. Curr. Biol. 19, 768-773. doi: 10.1016/j.cub.2009.03.022

Bussi, Y., Shimoni, E., Weiner, A., Kapon, R., Charuvi, D., Nevo, R., et al. (2019). Fundamental helical geometry consolidates the plant photosynthetic membrane. Proc. Natl. Acad. Sci. U. S. A. 116, 22366-22375. doi: 10.1073/ pnas.1905994116

Charuvi, D., Kiss, V., Nevo, R., Shimoni, E., Adam, Z., and Reich, Z. (2012). Gain and loss of photosynthetic membranes during plastid differentiation in the shoot apex of Arabidopsis. Plant Cell Online 24, 1143-1157. doi: 10.1105/ tpc.111.094458

Chastain, C. J., Failing, C. J., Manandhar, L., Zimmerman, M. A., Lakner, M. M., and Nguyen, T. H. T. (2011). Functional evolution of C4 pyruvate, orthophosphate dikinase. J. Exp. Bot. 62, 3083-3091. doi: 10.1093/jxb/err058

Chen, C., MacCready, J. S., Ducat, D. C., and Osteryoung, K. W. (2018). The Molecular Machinery of Chloroplast Division. Plant Physiol. 176, 138-151. doi: 10.1104/pp.17.01272

Chuong, S. D. X., Franceschi, V. R., and Edwards, G. E. (2006). The cytoskeleton maintains organelle partitioning required for single-cell $\mathrm{C} 4$ photosynthesis in Chenopodiaceae species. Plant Cell 18, 2207-2223. doi: 10.1105/tpc.105.036186

Danila, F. R., Danila, F. R., Quick, W. P., Quick, W. P., White, R. G., White, R. G., et al. (2016). The Metabolite Pathway between Bundle Sheath and Mesophyll: Quantification of Plasmodesmata in Leaves of C3 and C4 Monocots. Plant Cell Online 28, 1461-1471. doi: 10.1105/tpc.16.00155

Daum, B., and Kuhlbrandt, W. (2011). Electron tomography of plant thylakoid membranes. J. Exp. Bot. 62, 2393-2402. doi: 10.1093/jxb/err034

Daum, B., Nicastro, D., Austin, J., McIntosh, J. R., and Kühlbrandt, W. (2010). Arrangement of photosystem II and ATP synthase in chloroplast membranes of spinach and pea. Plant Cell Online 22, 1299-1312. doi: 10.1105/ tpc.109.071431

Dekker, J. P., and Boekema, E. J. (2005). Supramolecular organization of thylakoid membrane proteins in green plants. Biochim. Biophys. Acta. 1706, 12-39. doi: 10.1016/j.bbabio.2004.09.009

Demé, B., Cataye, C., Block, M. A., Maréchal, E., and Jouhet, J. (2014). Contribution of galactoglycerolipids to the 3-dimensional architecture of thylakoids. FASEB J. 28, 3373-3383. doi: 10.1096/fj.13-247395

Edwards, G. E., Franceschi, V. R., Ku, M. S., Voznesenskaya, E. V., Pyankov, V.II, and Andreo, C. S. (2001). Compartmentation of photosynthesis in cells and tissues of C(4) plants. J. Exp. Bot. 52, 577-590. doi: 10.1093/jexbot/52.356.577
Edwards, G. E., Franceschi, V. R., and Voznesenskaya, E. V. (2004). Single-cell C(4) photosynthesis versus the dual-cell (Kranz) paradigm. Annual. Rev. Plant Biol. 55, 173-196. doi: 10.1146/annurev.arplant.55.031903.141725

Erlinghaeuser, M., Hagenau, L., Wimmer, D., and Offermann, S. (2016). Development, subcellular positioning and selective protein accumulation in the dimorphic chloroplasts of single-cell C4species. Curr. Opin. Plant Biol. 31, 76-82. doi: 10.1016/j.pbi.2016.03.017

Evert, R. F., Eschrich, W., and Heyser, W. (1977). Distribution and structure of the plasmodesmata in mesophyll and bundle-sheath cells of Zea mays L. Planta 136, 77-89. doi: 10.1007/BF00387929

Evert, R. F., Russin, W. A., and Bosabalidis, A. M. (1996). Anatomical and ultrastructural changes associated with sink-to-source transition in developing maize leaves. Int. J. Plant Sci. 157, 247-261. doi: 10.1086/297344

Freitag, H., and Stichler, W. (2002). Bienertia cycloptera Bunge ex Boiss., Chenopodiaceae, another C4 Plant without Kranz Tissues. Plant Biol. 4, 121-132. doi: 10.1055/s-2002-20444

Gao, H., Sage, T. L., and Osteryoung, K. W. (2006). FZL, an FZO-like protein in plants, is a determinant of thylakoid and chloroplast morphology. Proc. Natl. Acad. Sci. U. S. A. 103, 6759-6764. doi: 10.1073/pnas.0507287103

Gowik, U., and Westhoff, P. (2011). The path from C3 to C4 photosynthesis. Plant Physiol. 155, 56-63. doi: 10.1104/pp.110.165308

Karahara, I., and Kang, B.-H. (2013). High-Pressure Freezing and Low-Temperature Processing of Plant Tissue Samples for Electron Microscopy, in Zarsky, V Cvrckova, F, editors. Plant Cell Morphogenesis. Methods Molecular Biology. Totowa, NJ: Humana Press, p. 147-157. doi: 10.1007/978-1-62703-643-6_12

Kirchhoff, H., Li, M., and Puthiyaveetil, S. (2017). Sublocalization of Cytochrome b6f Complexes in Photosynthetic Membranes. Trends Plant Sci. 22, 574-582. doi: $10.1016 /$ j.tplants.2017.04.004

Kirchhoff, H. (2018). Structure-function relationships in photosynthetic membranes_Challenges and emerging fields. Plant Sci. 266, 76-82. doi: 10.1016/j.plantsci.2017.09.021

Kobayashi, K., Narise, T., Sonoike, K., Hashimoto, H., Sato, N., Kondo, M., et al. (2013). Role of galactolipid biosynthesis in coordinated development of photosynthetic complexes and thylakoid membranes during chloroplast biogenesis in Arabidopsis. Plant J. 73, 250-261. doi: 10.1111/tpj.12028

Koteyeva, N. K., Voznesenskaya, E. V., Berry, J. O., Cousins, A. B., and Edwards, G. E. (2016). The unique structural and biochemical development of single cell C4 photosynthesis along longitudinal leaf gradients in Bienertia sinuspersici and Suaeda aralocaspica (Chenopodiaceae). J. Exp. Bot. 67, 2587-2601. doi: 10.1093/ jxb/erw082

Kowalewska, Ł., Mazur, R., Suski, S., Garstka, M., and Mostowska, A. (2016). Three-Dimensional Visualization of the Tubular-Lamellar Transformation of the Internal Plastid Membrane Network during Runner Bean Chloroplast Biogenesis. Plant Cell Online 28, 875-891. doi: 10.1105/tpc.15.01053

Langdale, J. A., Zelitch, I., Miller, E., and Nelson, T. (1988). Cell position and light influence $\mathrm{C} 4$ versus $\mathrm{C} 3$ patterns of photosynthetic gene expression in maize. EMBO J. 7, 3643-3651. doi: 10.1002/j.1460-2075.1988.tb03245.x

Lara, M. V., Offermann, S., Smith, M., Okita, T. W., Andreo, C. S., and Edwards, G. E. (2008). Leaf development in the single-cell C4 system in Bienertia sinuspersici: expression of genes and peptide levels for $\mathrm{C} 4$ metabolism in relation to chlorenchyma structure under different light conditions. Plant Physiol. 148, 593610. doi: 10.1104/pp.108.124008

Leegood, R. C. (2002). C4 photosynthesis: principles of CO2 concentration and prospects for its introduction into C3 plants. J. Exp. Bot. 53, 581-590. doi: $10.1093 /$ jexbot $/ 53.369 .581$

Li, P., Ponnala, L., Gandotra, N., Wang, L., Si, Y., Tausta, S. L., et al. (2010). The developmental dynamics of the maize leaf transcriptome. Nat. Genet. 42, 10601067. doi: 10.1038/ng.703

Liang, Z., Zhu, N., Mai, K. K., Liu, Z., Liu, Z., Tzeng, D., et al. (2018). Thylakoid-Bound Polysomes and a Dynamin-Related Protein, FZL, Mediate Critical Stages of the Linear Chloroplast Biogenesis Program in Greening Arabidopsis Cotyledons. Plant Cell Online 30, 1476-1495. doi: 10.1105/tpc.17.00972

Lindquist, E., Solymosi, K., and Aronsson, H. (2016). Vesicles are persistent features of different plastids. Traffic, 17, 1121-1138. doi: 10.1111/tra.12427

Ludwig, M. (2016). The Roles of Organic Acids in C4 Photosynthesis. Front. Plant Sci. 7, 251-311. doi: 10.3389/fpls.2016.00647 
Majeran, W., Majeran, W., Friso, G., Friso, G., Ponnala, L., Ponnala, L., et al. (2010). Structural and metabolic transitions of C4 leaf development and differentiation defined by microscopy and quantitative proteomics in maize. Plant Cell Online 22, 3509-3542. doi: 10.1105/tpc.110.079764

Mai, K. K. K., Yeung, W.-T., Han, S.-Y., Cai, X., Hwang, I., and Kang, B.-H. (2019). Electron Tomography Analysis of Thylakoid Assembly and Fission in Chloroplasts of a Single-Cell C4 plant, Bienertia sinuspersici. Sci. Rep. 9, 19640. doi: 10.1038/s41598-019-56083-w

Mertz, R. A., and Brutnell, T. P. (2014). Bundle sheath suberization in grass leaves: multiple barriers to characterization. J. Exp. Bot. 65, 3371-3380. doi: 10.1093/ jxb/eru108

Minges, A., Janßen, D., Offermann, S., and Groth, G. (2019). Efficient In Vivo Screening Method for the Identification of C4 Photosynthesis Inhibitors Based on Cell Suspensions of the Single-Cell C4 Plant Bienertia sinuspersici. Front. Plant Sci. 10, 290-210. doi: 10.3389/fpls.2019.01350

Mustárdy, L., Buttle, K., Steinbach, G., and Garab, G. (2008). The ThreeDimensional Network of the Thylakoid Membranes in Plants: Quasihelical Model of the Granum-Stroma Assembly. Plant Cell 20, 2552-2557. doi: 10.1105/tpc.108.059147

Nevo, R., Charuvi, D., Tsabari, O., and Reich, Z. (2012). Composition, architecture and dynamics of the photosynthetic apparatus in higher plants. Plant J. 70, 157-176. doi: 10.1111/j.1365-313X.2011.04876.x

Offermann, S., Okita, T. W., and Edwards, G. E.. (2011). Resolving the compartmentation and function of $\mathrm{C} 4$ photosynthesis in the single-cell C4 species Bienertia sinuspersici. Plant Physiol. 155, 1612-1628. doi: 10.1104/ pp.110.170381

Offermann, S., Friso, G., Doroshenk, K. A., Sun, Q., Sharpe, R. M., Okita, T. W., et al. (2015). Developmental and Subcellular Organization of Single-Cell C 4Photosynthesis in Bienertia sinuspersiciDetermined by Large-Scale Proteomics and cDNA Assembly from 454 DNA Sequencing. J. Proteome Res. 14, 2090-2108. doi: 10.1021/pr5011907

Osteryoung, K. W., and Pyke, K. A. (2014). Division and Dynamic Morphology of Plastids. Annu. Rev. Plant Biol. 65, 443-472. doi: 10.1146/annurev-arplant050213-035748

Park, J., Knoblauch, M., Okita, T. W., and Edwards, G. E. (2008). Structural changes in the vacuole and cytoskeleton are key to development of the two cytoplasmic domains supporting single-cell C4 photosynthesis in Bienertia sinuspersici. Planta 229, 369-382. doi: 10.1007/s00425-008-0836-8

Pogson, B. J., Ganguly, D., and Albrecht-Borth, V. (2015). Insights into chloroplast biogenesis and development. BBA - Bioenerg. 1847, 1017-1024. doi: 10.1016/ j.bbabio.2015.02.003

Pribil, M., Sandoval-Ibáñez, O., Xu, W., Sharma, A., Labs, M., Liu, Q., et al. (2018). Fine-Tuning of Photosynthesis Requires CURVATURE THYLAKOID1Mediated Thylakoid Plasticity. Plant Physiol. 176, 2351-2364. doi: 10.1104/ pp.17.00863

Rao, X., and Dixon, R. A. (2016). The Differences between NAD-ME and NADPME Subtypes of C4 Photosynthesis: More than Decarboxylating Enzymes Front. Plant Sci. 7, 805-809. doi: 10.3389/fpls.2016.01525

Rocha, J., Nitenberg, M., Girard-Egrot, A., Jouhet, J., Maréchal, E., Block, M. A., et al. (2018). Do galactolipid synthases play a key role in the biogenesis of chloroplast membranes of higher plants? Front. Plant Sci. 9, 126. doi: 10.3389/ fpls.2018.00126

Rudowska, L., Gieczewska, K., Mazur, R., Garstka, M., and Mostowska, A. (2012). Chloroplast biogenesis - correlation between structure and function. Biochim. Biophys. Acta 1817, 1380-1387. doi: 10.1016/j.bbabio.2012.03.013

Sedelnikova, O. V., Hughes, T. E., and Langdale, J. A. (2018). Understanding the Genetic Basis of C $4 \mathrm{Kranz}$ Anatomy with a View to Engineering C 3Crops. Annu. Rev. Genet. 52, 249-270. doi: 10.1146/annurev-genet-120417-031217

Seiwert, D., Witt, H., Ritz, S., Janshoff, A., and Paulsen, H. (2018). The Nonbilayer Lipid MGDG and the Major Light-Harvesting Complex (LHCII) Promote Membrane Stacking in Supported Lipid Bilayers. Biochemistry 57, 2278-2288. doi: 10.1021/acs.biochem.8b00118
Sharpe, R. M., and Offermann, S. (2013). One decade after the discovery of singlecell C4 species in terrestrial plants: what did we learn about the minimal requirements of C4 photosynthesis? Photosynth. Res. 119, 169-180. doi: 10.1007/ s11120-013-9810-9

Shimoni, E., Rav-Hon, O., Ohad, I., Brumfeld, V., and Reich, Z. (2005). Threedimensional organization of higher-plant chloroplast thylakoid membranes revealed by electron tomography. Plant Cell 17, 2580-2586. doi: 10.1105/ tpc. 105.035030

Staehelin, L. A. (2003). Chloroplast structure: from chlorophyll granules to supramolecular architecture of thylakoid membranes. Photosynth. Res. 76, 185-196. doi: 10.1023/A:1024994525586

Staehelin, L. A., and Kang, B.-H. (2008). Nanoscale architecture of endoplasmic reticulum export sites and of Golgi membranes as determined by electron tomography. Physiol. 147, 1454-1468. doi: 10.1104/pp.108.120618

Tausta, S. L., Li, P., Si, Y., Gandotra, N., Liu, P., Sun, Q., et al. (2014). Developmental dynamics of Kranz cell transcriptional specificity in maize leaf reveals early onset of C4-related processes. J. Exp. Bot. 65, 3543-3555. doi: 10.1093/jxb/eru152

Terasaki, M., Shemesh, T., Kasthuri, N., Klemm, R. W., Schalek, R., Hayworth, K. J., et al. (2013). Stacked endoplasmic reticulum sheets are connected by helicoidal membrane motifs. Cell 154, 285-296. doi: 10.1016/j.cell.2013.06.031

Voznesenskaya, E. V., Franceschi, V. R., Pyankov, V.II, and Edwards, G. E. (1999). Anatomy, chloroplast structure and compartmentation of enzymes relative to photosynthetic mechanisms in leaves and cotyledons of species in the tribe Salsoleae (Chenopodiaceae). J. Exp. Bot. 50, 1779-1795. doi: 10.1093/jxb/ 50.341.1779

Voznesenskaya, E. V., Franceschi, V. R., Kiirats, O., Freitag, H., and Edwards, G. E. (2001). Kranz anatomy is not essential for terrestrial C4 plant photosynthesis. Nature 414, 543-546. doi: 10.1038/35107073

Voznesenskaya, E. V., Koteyeva, N. K., Chuong, S. D. X., Akhani, H., Edwards, G. E., and Franceschi, V. R. (2005). Differentiation of cellular and biochemical features of the single-cell C4 syndrome during leaf development in Bienertia cycloptera (Chenopodiaceae). Am. J. Bot. 92, 1784-1795. doi: 10.3732/ ajb.92.11.1784

Wang, L., Czedik-Eysenberg, A., Mertz, R. A., Si, Y., Tohge, T., Nunes-Nesi, A., et al. (2014). Comparative analyses of C4 and C3 photosynthesis in developing leaves of maize and rice. Nat. Biotechnol. 32, 1158-1164. doi: 10.1038/ ncomms 12569

Wang, Y., Zhang, Y., Chen, L., Liang, Q., Yin, X.-M., Miao, L., et al. (2016). Kinetics and specificity of paternal mitochondrial elimination in Caenorhabditis elegans. Nat. Commun. 7, 12569. doi: 10.1038/ncomms12569

Wang, P., Chen, X., Goldbeck, C., Chung, E., and Kang, B.-H. (2017). A distinct class of vesicles derived from the trans-Golgi mediates secretion of xylogalacturonan in the root border cell. Plant J. 92, 596-610. doi: 10.1111/ tpj.13704

Wang, P., Liang, Z., and Kang, B.-H. (2019). Electron tomography of plant organelles and the outlook for correlative microscopic approaches. New Phytol. 223, 1756-1761. doi: 10.1111/nph.15882

Wimmer, D., Bohnhorst, P., Shekhar, V., Hwang, I., and Offermann, S. (2017). Transit peptide elements mediate selective protein targeting to two different types of chloroplasts in the single-cell C4 species Bienertia sinuspersici. Sci. Rep. 7, 41187. doi: 10.1038/srep41187

Conflict of Interest: The authors declare that the research was conducted in the absence of any commercial or financial relationships that could be construed as a potential conflict of interest.

Copyright (C) 2020 Mai, Gao and Kang. This is an open-access article distributed under the terms of the Creative Commons Attribution License (CC BY). The use, distribution or reproduction in other forums is permitted, provided the original author(s) and the copyright owner(s) are credited and that the original publication in this journal is cited, in accordance with accepted academic practice. No use, distribution or reproduction is permitted which does not comply with these terms. 